\title{
CRiando, CONTANdo E (EN)CANTANDo: Composições DE INTERAÇÃO POÉTICA
}

\author{
CREATING, TELLING AND (EN)CHANTING: COMPOSITIONS OF POETIC \\ INTERACTION
}

DOI: $\underline{\text { 10.23926/RPD.2526-2149.2020.v5.n3.p1612-1626.id856 }}$

\section{Ricardo Ferreira de Sousa \\ Mestrando em Letras (UFT) \\ Especialista em Linguística \\ Aplicada na Educação \\ (UCAM) \\ ricardof@uft.edu.br}

\section{Neila Nunes de Souza \\ Doutora em Educação (UnB) Professora do Programa de Pós-Graduação em Letras da Universidade Federal do Tocantins (UFT) neilansouza@uft.edu.br}

\begin{abstract}
Resumo: O presente artigo é resultado de uma prática docente realizada junto ao projeto intitulado "Sarau literomusical: poesia, arte e música", que aconteceu no âmbito da componente curricular de Língua Portuguesa no segundo semestre letivo do ano de 2019, no Colégio da Polícia Militar, Palmas, estado do Tocantins. Nesse sentido, o nosso objetivo é apresentar considerações relevantes acerca do Sarau, discutir sobre a postura investigativa e crítica do aluno e propor uma reflexão sobre a ampliação das práticas pedagógicas, via projetos, fortalecidos na participação e autoria dos envolvidos. Assim, o estudo apresenta o gênero textual poema como suporte central e articulador das atividades de ensino. O percurso vivenciado proporcionou um rico processo de ensino-aprendizagem que resultou no desenvolvimento de habilidades e competências essenciais para o trabalho docente: planejamento, pesquisa e momentos de ponderações críticas. Trataremos aqui de um evento que aborda os mecanismos de leitura, escrita, criação e exposição de poemas.
\end{abstract}

Palavras-chave: Leitura. Poema. Ensino. Interação.

\begin{abstract}
The present paper is a result practice teaching action conducted on the project entitled "Sarau literomusical: poesia, arte e música", that happened on the Portuguese Language curriculum area during the second semester of 2019 at the Colégio da Policia Militar of Palmas, Tocantins state. Therefore, this text intends to present relevant appointments regarding Sarau and to highlight the investigative and critic approach of the student, as well as to propose a reflection on the expansion of the pedagogical practices via projects strengthened on participation and protagonism of people involved. Further on, this study presents the poem text genre as central support and articulator of teaching activities. The tracking experienced provided rich teaching-learning process, which resulted in the development of skills and competencies essential for teaching work: planning, research and moments of clinical consideration. It will be discussed here, therefore, an event which approaches reading, writing, creating and exposing poems mechanisms.
\end{abstract}

Keywords: Reading. Poem. Teaching. Interaction. 


\section{INTRODUÇÃO}

Entende-se por Sarau como um evento cultural em que as pessoas realizam apresentações musicais, danças, recitações de poemas e encenações teatrais, momentos assim favorece a imaginação e atuação do sujeito, residindo no pensar, refletir e entreter-se culturalmente em torno das temáticas apresentadas, na qual se valorizam os eixos da oralidade, escrita, leitura e o pluralismo de idéias associadas às práticas de vivências. Nesse contexto, o projeto intitulado "Sarau literomusical: poesia, arte e música" idealizadas como objeto de estudo, foi consolidado num espaço cultural para que os alunos do Colégio da Polícia Militar de Palmas (CPM) ${ }^{1}$, estado do Tocantins, pudessem compartilhar e apreciar expressões artísticoculturais próprias e de outros artistas. A intenção é que a ação proporcionasse momentos de socialização, convivência e trocas de experiências, no sentido de tornar o ensino mais interativo e a aprendizagem mais humanizada.

Em consonância com o Programa Jovem em Ação da Secretaria de Educação, Juventude e Esportes do estado do Tocantins (SEDUC-TO), no projeto Sarau, procuramos refletir e contribuir para a formação dos alunos do colégio em questão, envolvendo-os com os fatores interativos e presumindo a propagação investigativa de valores que permeiam na sociedade.

Dessa forma, este artigo busca apresentar algumas considerações sobre a ação desenvolvida, cujo propósito maior será de trazer apontamentos reflexivos sobre a ampliação das práticas pedagógicas, via projetos, fortalecidas na participação, autonomia, postura investigativa e crítica do aluno. O gênero textual poema, compreendido como instância maior da ação e como ferramenta didática, permite que o professor desenvolva com seus alunos habilidades e competências de leitura e escrita, justificando o trabalho no ensejo de situações reais de práticas letradas como parte do contexto local, das experiências sociais e da capacidade crítica-reflexiva do alunado frente às questões diversas. Nessa prática, o contato com textos usuais permite a construção de diferentes sentidos e significados que favorecem a aprendizagem.

$\mathrm{O}$ ato de pensar, criar e atuar nos espaços formativos permite a compreensão dos fatos, da história e da vida. Logo, as formas de ensinar devem dialogar com esses aspectos de modo que os professores sejam instigados a levarem os alunos à reflexão, em que possam agir ativamente e a escola, como lócus de ensino e aprendizagem, é o lugar ideal para que esse

\footnotetext{
${ }^{1}$ O Colégio da Polícia Militar de Palmas, Tocantins, localiza-se no seguinte endereço: Quadra 206 Norte, QI. 301 Norte Avenida LO, 4 - Lote 04 - Plano Diretor Norte, Palmas - TO, 77006-244.
} 
encontro aconteça. Partindo desse ponto de vista, o Sarau desperta nos alunos a diversidade literária e artística, além do gosto pela leitura e pela produção cultural.

Neste espaço de construção, o educando é tomado como um ser socialmente histórico, capaz de construir seu mundo e transformar sua volta, pois, é por meio da linguagem que o homem se expressa e a compreensão de mundo se faz pela palavra. Bakhtin (2003) assevera que a linguagem é um sistema de interação verbal, segundo o autor é no contexto social que ela se instaura para mediar relações sociais com o sujeito que se constitui no seu lugar historicamente construído. Destarte, é premente uma transformação no modo como as aulas de Língua Portuguesa são conduzidas, de maneira a concentrar atenções em concepções de aprendizados intersubjetivas e dialógicas com a finalidade de estimular práticas de linguagens efetivamente críticas.

Assim, seguida desta introdução, esse texto possui cinco partes: primeiro discorremos sobre o gênero poema contextualizando-o na prática do conhecimento, em seguida, apresentamos os procedimentos metodológicos na realização do projeto e no propósito deste relato, na sequência, tratamos dos resultados com descrição e análise de dados e, por fim, expomos as considerações finais e referências. Para o cumprimento dos objetivos, a descrição e análise da prática sustentam-se com base na fundamentação teórica centrada nos seguintes estudiosos: Bakhtin (2003), Rojo e Moura (2012), Kleiman (2000), Moita Lopes (1994), Freire (1996), Lajolo (2002), entre outros.

\section{BREVE CONTEXTUALIZAÇÃo DO TRABALHO COM O GÊNERO POEMA}

Segundo os Parâmetros Curriculares Nacionais (BRASIL, 1998) o trabalho com os gêneros literários em sala de aula constitui sentido de forma peculiar de representação e estilo, em que predominam a força criativa da imaginação e a intenção estética. Além disso, o gênero se destaca pela manifestação sociocultural do poético no mundo, nas artes e nas palavras.

O gênero, pois, se bem trabalhado, permitem aos sujeitos envolvidos uma melhor compreensão da realidade, em um diálogo de vozes marcantes, tendo espaço constante para a emoção, para a sensibilidade, para a (re)construção dos saberes que ocorrem por meio da interação e pelos diferentes signos linguísticos envolvidos no processo de ensino e aprendizagem. Diante disso, é necessário que o professor tenha conhecimentos acerca da importância de se trabalhar não apenas a função verbal, mas, sobretudo, a função social do poema no ambiente escolar, pois um texto literário é carregado de sentidos e o aluno deve recriálos para si e para o outro. Isso implica afirmar que os significados com que trabalhamos na 
sociedade são produtos de um movimento histórico, localizados culturalmente e institucionalmente (MOITA LOPES, 1994, p. 361).

De acordo com Silva (2011), essa atividade corresponde à concepção de mundo baseada em composições poéticas que buscam interpretar e compreender a realidade na voz do sujeito.

\begin{abstract}
Ensinar poesia (em todos os seus subgêneros) é trabalhar o texto como resposta a uma necessidade, a alguém (o leitor), a um tempo definido. A poesia dentro dessa concepção é um modo de viver o mundo (ver, sentir, experimentar e projetar) e cada composição poética reflete quem somos, o que pensamos, sentimos e buscamos. Ocupar-se com a poesia porque ela auxilia na construção de um cidadão leitor, de um leitor capaz de interpretar o mundo ao seu redor, que encontra na poesia a sua própria realidade social, essa é a perspectiva defendida neste trabalho que se dispõe a fazer (SILVA, 2011, p. 24).
\end{abstract}

A partir do que foi exposto, ressaltamos que o poema é criado como se fosse um jogo de palavras. Ele motiva o leitor a descobrir não apenas a leitura corrente, mas também a buscar outras leituras possíveis. Compreendemos isso a partir da perspectiva que o poeta busca mostrar o mundo de um jeito novo, com a intenção de sensibilizar, convencer, fazer pensar ou divertir os leitores. O poeta é o artista que usa as palavras para fazer uma obra de arte - o poema.

Nas palavras da professora Marisa Lajolo ${ }^{2}$

[...] um poema é um jogo com a linguagem. Compõe-se de palavras: palavras soltas, palavras empilhadas, palavras em fila, palavras desenhadas, palavras em ritmo diferente da fala do dia a dia. Além de diferentes pela sonoridade e pela disposição na página, os poemas representam uma maneira original de ver o mundo, de dizer coisas [...] poeta é, assim, quem descobre e faz poesia a respeito de tudo: de gente, de bicho, de planta, de coisas do dia a dia da vida da gente, de um brinquedo, de pessoas que parecem com pessoas que conhecemos de episódios que nunca imaginamos que poderiam acontecer e até a própria poesia! (LAJOLO, 2002, p. 21).

Nesse sentido, ao recitar um poema, estamos falando do próprio discurso poético. Por outro lado, o termo poesia remete-se ao fato de que todo artista é capaz de tornar poética uma obra de arte. Um filme, um balé, uma cena teatral, um trecho de romance ou de um texto opinativo, um quadro, uma gravura ou uma obra musical pode ter poesia e produzir efeito poético. Em síntese, o poema é uma manifestação do discurso poético em um texto e a poesia é qualquer tipo de efeito produzido pela linguagem.

Ao trabalhar o Sarau articulado ao gênero literário poema, estimula-se o gosto pela leitura ao mesmo tempo em que mobiliza o aluno a desenvolver suas habilidades poéticas e artísticas. Dessa forma, a atividade docente passa a agir no sentido de promover práticas de

\footnotetext{
${ }^{2}$ Veja as contribuições da autora no Caderno Poetas da Escola do Programa Escrevendo o Futuro, da Olimpíada de Língua Portuguesa, disponível em: https://www.escrevendoofuturo.org.br/
} 
letramento, isto é, práticas sociais de leitura e escrita permeadas pela comunicação e interação oportunizando a conexão entre as realidades dos alunos e o contexto escolar.

$\mathrm{Na}$ perspectiva de trabalhar com projetos que envolvem práticas de letramentos, Kleiman (2000) apresenta a seguinte proposição:

\begin{abstract}
Assim, um projeto de letramento se constitui como "um conjunto de atividades que se origina de um interesse real na vida dos alunos e cuja realização envolve o uso da escrita, isto é, a leitura de textos que, de fato, circulam na sociedade e a produção de textos que serão realmente lidos, em um trabalho coletivo de alunos e professor, cada um segundo sua capacidade" (KLEIMAN, 2000, p. 227).
\end{abstract}

O trabalho do professor é, portanto, de estimular a expressão criativa do aluno, desenvolver habilidades que lhes permitam ler e escrever com mais segurança, de modo que o trabalho seja valorizado e harmonioso, relacionando os aprendizados sociais e históricos da leitura e da escrita em contextos utilitários (MARCUSCHI, 2003, p. 21).

\title{
3 Procedimentos Metodológicos
}

Apresentamos neste momento o método que define o desenho do projeto exposto inicialmente. Quando se fala em método, busca-se explicitar quais os motivos pelos quais o pesquisador escolheu determinados caminhos e não outros (CARVALHO, 2000), e o conhecimento científico é fonte essencial para questionar a realidade, buscando compreendê-la e explicá-la. Sob esse viés, o estudo trata-se de um relato de prática docente em que os dados foram apresentados e analisados em um simples gesto de interpretação. O aporte teóricometodológico consiste na pesquisa de campo in lócus, atrelada a dados bibliográficos que sustentam o relato de prática docente disponibilizadas no decorrer do texto. Sendo assim, esse procedimento propicia um estudo mais aprofundado acerca do objeto de pesquisa, chegando à compreensão e interpretação de novos resultados que ultrapassa o senso comum (DESLANDES, 2009).

O projeto parte do planejamento e organização baseado no contexto de vida dos alunos. As atividades contemplam apresentações culturais, cuja proposta foi adaptada do livro didático de Língua Portuguesa do $1^{\circ}$ ano do Ensino Médio para a realidade dos alunos e da escola. Dessa forma, o professor idealizador parte das seguintes finalidades específicas:

- Estimular o desenvolvimento crítico do aluno, despertando nele o prazer pela leitura, escrita e oratória;

- Inserir o aluno no processo de criação poética;

- Despertar no aluno o senso crítico e estético para apreciação da poesia como arte literária; 
- Contribuir para que os alunos conheçam e utilizem elementos constitutivos da linguagem de forma reflexiva e funcional, sendo caracterizado como um evento onde as pessoas se encontram para se expressar e/ou se manifestar artisticamente.

A Sequência Didática (SD) desenvolvida no projeto aconteceu conforme são apresentados no cronograma abaixo (Quadro 1), respeitando o período de início e término das atividades (06/08/2019 a 24/09/2019), correspondendo a 22 aulas de 50 minutos cada. Também são apresentadas a seguir, as atribuições da práxis docente e do alunado para a realização do evento (Quadro 2).

Quadro 1 - Cronograma de atividades

\begin{tabular}{|c|c|}
\hline \multicolumn{2}{|r|}{ Sequência Didática (SD) } \\
\hline Encontros & Etapas \\
\hline 06/08/2019 & $\begin{array}{l}\text { Apresentação da proposta para os alunos; divisão dos grupos e seleção dos temas para a } \\
\text { investigação. }\end{array}$ \\
\hline $13 / 08 / 2019$ & $\begin{array}{l}\text { Estudo acerca do gênero poema: definição; características; elementos estruturais do } \\
\text { texto; aspectos verbais e sociais do gênero. }\end{array}$ \\
\hline 19/08/2019 & $\begin{array}{l}\text { Estudo da apostila de nivelamento: Campo artístico-literário: gêneros poéticos - poema } \\
\text { visual, cordel e slam. }\end{array}$ \\
\hline 21/08/2019 & $\begin{array}{l}\text { Leitura e análise de soneto do poeta português Luís Vaz de Camões e poemas de Carlos } \\
\text { Drummond de Andrade, entre outros. }\end{array}$ \\
\hline $27 / 08 / 2019$ & Organização dos grupos e início da produção dos poemas de forma coletiva. \\
\hline 28/08/2019 & Escrita: término dos poemas e entrega para o professor. \\
\hline 02/09/2019 & Reescrita: devolutiva do poema para ajustes e finalização do gênero. \\
\hline $\begin{array}{l}10 / 09 / 2019 \text { e } \\
11 / 09 / 2019\end{array}$ & Ensaios coletivos: caracterização, encenação e declamação para a apresentação cultural. \\
\hline $19 / 092019$ & $\begin{array}{l}\text { Organização do material de caracterização do Sarau e de ornamentação do local das } \\
\text { apresentações (auditório do colégio). }\end{array}$ \\
\hline 24/09/2019 & $\begin{array}{l}\text { Culminância cultural do Sarau Literomusical envolvendo alunos e professores de } 1^{\mathrm{a}} \\
\text { séries. }\end{array}$ \\
\hline
\end{tabular}

Fonte: Elaborado pelos autores, 2020.

Quadro 2 - Atribuições do professor e do aluno

\begin{tabular}{|c|c|}
\hline & \\
\hline $\begin{array}{l}\text { - Apresentar o gênero textual para os alunos, } \\
\text { conceituando e abordando os níveis socioculturais } \\
\text { do poema; } \\
\text { - Realizar a leitura e análise de poemas da literatura } \\
\text { nacional e local; } \\
\text { - Abordar os aspectos verbais e sociais do poema; } \\
\text { - Auxiliar os alunos na elaboração dos poemas e } \\
\text { organizá-los em grupos conforme as temáticas e } \\
\text { oficinas; } \\
\text { - Desenvolver a culminância do Sarau com } \\
\text { apresentações culturais; } \\
\text { - Avaliar o processo e o produto final. }\end{array}$ & $\begin{array}{l}\text { - Reconhecer o Sarau e o gênero poema como uma } \\
\text { espécie de evento cultural; } \\
\text { - Participar ativamente das práticas de letramento de } \\
\text { forma prazerosa e interativa; } \\
\text { - Praticar a escrita e reescrita dos textos autorais } \\
\text { (produção de poema); } \\
\text { - Valorizar a criação de poemas, bem como a sua } \\
\text { relevância na formação interpessoal e social; } \\
\text { - Declamar, encenar e caracterizar-se } \\
\text { adequadamente à proposta apresentada; } \\
\text { - Participar das oficinas e da atividade cultural de } \\
\text { culminância. }\end{array}$ \\
\hline
\end{tabular}

Fonte: Elaborado pelos autores, 2020. 
Nessa perspectiva, o projeto de ensino envolve alunos de três turmas da $1^{\circ}$ série, valorizando o papel discente e sua voz, bem como, o agir docente, ao considerar em uma dimensão discursiva o ensino como trabalho integralizado e (trans)formador. Em suma, o Sarau literário abordou o fazer poético do aluno. O processo aconteceu por meio de cinco passos constitutivos: 1) estudo sobre o gênero textual poema; 2) elaboração de poemas pelos alunos (escrita e reescrita); 3) encenação e exposição acerca da temática em ritmo musical, valorizando a expressão corporal; 4) caracterização de acordo com as temáticas desenvolvidas e; 5) apresentação cultural para a comunidade escolar.

Para alinharmos o objeto do conhecimento, pautamos no Campo artístico-literário: gêneros poéticos - poema visual, cordel e slam, centralizando com o gênero apresentado no livro didático, em que o processo possibilitou estudar as particularidades do poema a nível estrutural e de conteúdo, valorizando os aspectos verbais e sociais do texto.

\section{RESUltados DA AÇÃo: DESCRIÇÃo E ANÁLISE}

O Sarau literário foi realizado no dia 24 de setembro do ano de 2019, durante os horários da disciplina de Língua Portuguesa do/pelo professor idealizador da ação. As atividades tiveram início no mês de agosto quando a proposta foi apresentada e, em seguida, foi efetivado um trabalho contínuo e formativo com duração de dois meses até a sua conclusão. Na culminância, o projeto contou com mais de 150 pessoas que prestigiaram o evento, voltado, exclusivamente, para os alunos da $1^{\mathrm{a}}$ série do Ensino Médio. No entanto, outros alunos também participaram da ação, além de professores, equipe da coordenação geral e da área de linguagens do Colégio da Polícia Militar.

A programação contou com 16 apresentações - declamação de poemas, encenações teatrais e apresentações musicais dos discentes das turmas 13.01, 13.02 e 13.03, atores centrais do projeto. Os alunos produziram 28 poemas, que foram dispostos para apreciação do público durante a culminância. A seguir apresentamos a frente de um folder que contém informações sobre o evento (Figura 1). 
Figura 1 - Folder informativo da programação do evento

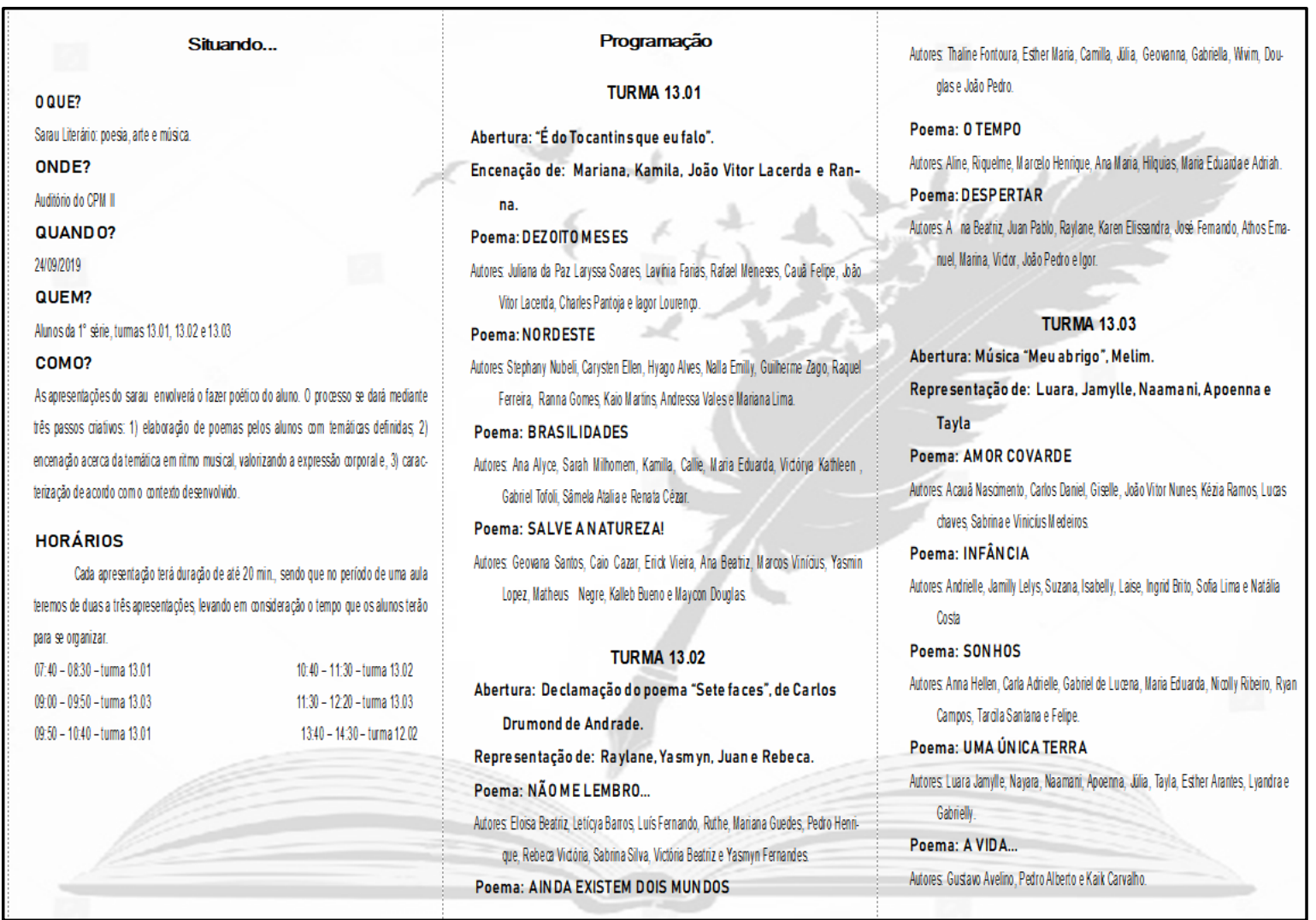

Fonte: Elaborado pelos autores, 2019.

Em cada turma, formaram-se grupos de seis e sete alunos, estes ficaram responsáveis pela produção coletiva de um poema temático em datas e horários definidos pelo professor. Para uma melhor forma composicional, estilo e conteúdo, a pedido do professor, o grupo deveria reescrevê-lo, adaptando-o conforme direcionamentos.

Durante o período de construção do projeto, em aulas teóricas e práticas sequenciais, os alunos tiveram contato com alguns poemas para a compreensão dos mecanismos verbais e sociais, como: Amor é fogo que arde sem ver, de Luís Vaz de Camões, Humildade, de Cora Coralina, Poema Sete Faces e José, de Carlos Drummond de Andrade e Convite, de José Paulo Paes. Importa dizer que os alunos tiveram autonomia para a escolha dos poemas que refletissem suas vivências. A propósito, das aulas sempre estiveram voltadas para as situações cotidianas dos alunos e eles foram instigados a pensar em formas reais e problemáticas na qual os autores situavam nos textos.

Atendendo a Sequência Didática proposta para trabalhar com o Sarau, de início o professor realiza o levantamento de conhecimentos prévios sobre o gênero, ou seja, procura saber se os alunos possuem conhecimento sobre o gênero textual poema, como características e autores, bem como se possuem práticas de leitura desse tipo de texto. Para a socialização em 
sala de aula, leva-se em consideração o processo de construção dos alunos, assim, compreender a linguagem, os recursos expressivos e estilísticos, associar a temática ao cotidiano, fazer comparações, intervenções, entre outras, significa levar o aluno à posterior compreensão, interpretação e análise do gênero, um momento extremamente rico em que aprendemos e interagimos com o texto em uma perspectiva intersubjetiva, dialógica, responsiva, ativa e multicultural (ROJO; MOURA, 2012, p. 12).

Diante da produção escrita, os alunos focaram em situações cotidianas e produziram os poemas em coletivo. Nesse sentido, para aproximar a produção escrita das necessidades enfrentadas no dia a dia, o caminho geralmente é enfocar o desenvolvimento dos comportamentos leitores e escritores. $\mathrm{O}$ trabalho com um gênero em sala de aula é o resultado de uma decisão didática que visa proporcionar ao aluno conhecê-lo melhor, apreciá-lo e compreendê-lo para que ele seja capaz de produzir na escola ou fora dela. Tomado por essa realidade, Sercundes $(1997$, p. 76$)$ acrescenta que "o trabalho de escrever aparece como uma consequência natural das informações disponíveis". Posto isso, é possível compreender a imagem de que os alunos são sujeitos que apresentam desenvoltura com a escrita, entendidos como detentores de um dom acometidos de momentos de inspiração, na qual o articulador das etapas individuais e grupais é o professor, que acompanha, orienta e analisa o processo percorrido, bem como avalia os resultados. Essa atenção diária é primordial para o desenvolvimento de uma boa aula.

Posto isso, por meio da escrita de poemas, os alunos expressaram seus sentimentos, indignações e inquietações, trazendo para esse momento de reflexão sociocultural a discussão sobre temas de educação ambiental, políticas públicas, cultura popular, arte e literatura de regiões do Brasil e da comunidade local, oportunizando-lhes o diálogo para além da sala de aula.

Chegado o dia da culminância, cada apresentação teve duração de 15 a 20 minutos, sendo que no período de uma aula de 50 minutos, tivemos de duas a três apresentações, isto é, levando em consideração o tempo que os alunos tiveram para se organizar. A concretização do projeto contou com declamações, encenações e apresentações musicais, promovendo uma produtiva interação entre alunos e professores que dialogam com expressões artísticas variadas. No momento em que acontece a apresentação cultural, todos os alunos assumem um papel de protagonistas, todos têm uma função a desempenhar nesta prática socialmente significativa e relevante. Nessa tendência, o evento fomenta as discussões escolares e a formação de sujeitos críticos. Esse processo é transformador na vida do aluno, onde ele busca (re)produzir práticas 
de vivências em grupo e ao evidenciar o letramento local - regional, é fazê-lo pensar nele e a partir dele transformá-lo. Reconhece também que essas práticas se estabelecem em contextos sociais e culturais diversificados com a participação de sujeitos igualmente inseridos em realidades e experiências diversas.

Após o evento, foi realizado um feedback com os alunos. Oralmente eles expuseram as sensações e percepções das apresentações realizadas. Segundo as falas, o Sarau possibilitou maior interação entre alunos e alunos, alunos e professor, trazendo benefícios para o convívio coletivo e para a aprendizagem. Os alunos avaliaram o projeto como uma importante atividade que foge do tradicionalismo (ler, escrever, copiar tarefas, etc.) e aprendem muito mais com as trocas de experiências. Nessa relação, o imperativo dado pelo Aluno Y foi: "Professor, queremos outro Sarau com o Senhor". A proposta do Sarau é, sim, um projeto que acontecerá anualmente.

Os anseios foram muitos por ambas as partes. Para os alunos, a tensão estava na apresentação cultural, se para alguns essa prática já fazia parte da vida, para outros era um desafio a ser vencido, pois muitos se sentiam nervosos, ansiosos e até pensavam em desistência. No entanto, acreditaram na qualidade do trabalho que estávamos realizando e diante do compromisso, o resultado não poderia ser diferente, senão o produto excelente de apresentações contextualizadas e direcionadas para o momento atual. Para o professor, a expectativa era enorme, atuou no potencial de seus alunos, preparando e lançando-os na prática discursiva. A sensação final foi de dever cumprido e orgulho pela qualidade e realização do trabalho. O Sarau foi um evento ímpar e cumpriu as expectativas idealizadas, houve muita dedicação dos alunos, o que tornou satisfatório o planejamento da disciplina, o que nos faz refletir sobre as competências e habilidades na classe de ensino e sobre a linguagem (oral e escrita) enquanto função social e comunicativa das relações entre os interlocutores. Nesse contexto, o professor buscou proporcionar prazer pela atividade leitora e escrita e os alunos foram levados (re)produzir sentidos e dialogá-los com a vida.

O processo avaliativo como parte da atividade, deu-se de forma contínua de acordo com os fatores procedimentais e atitudinais de participação, organização e interação dos grupos na realização do projeto.

Segue evidências do dia da culminância do Sarau (Figuras 2 e 3) 


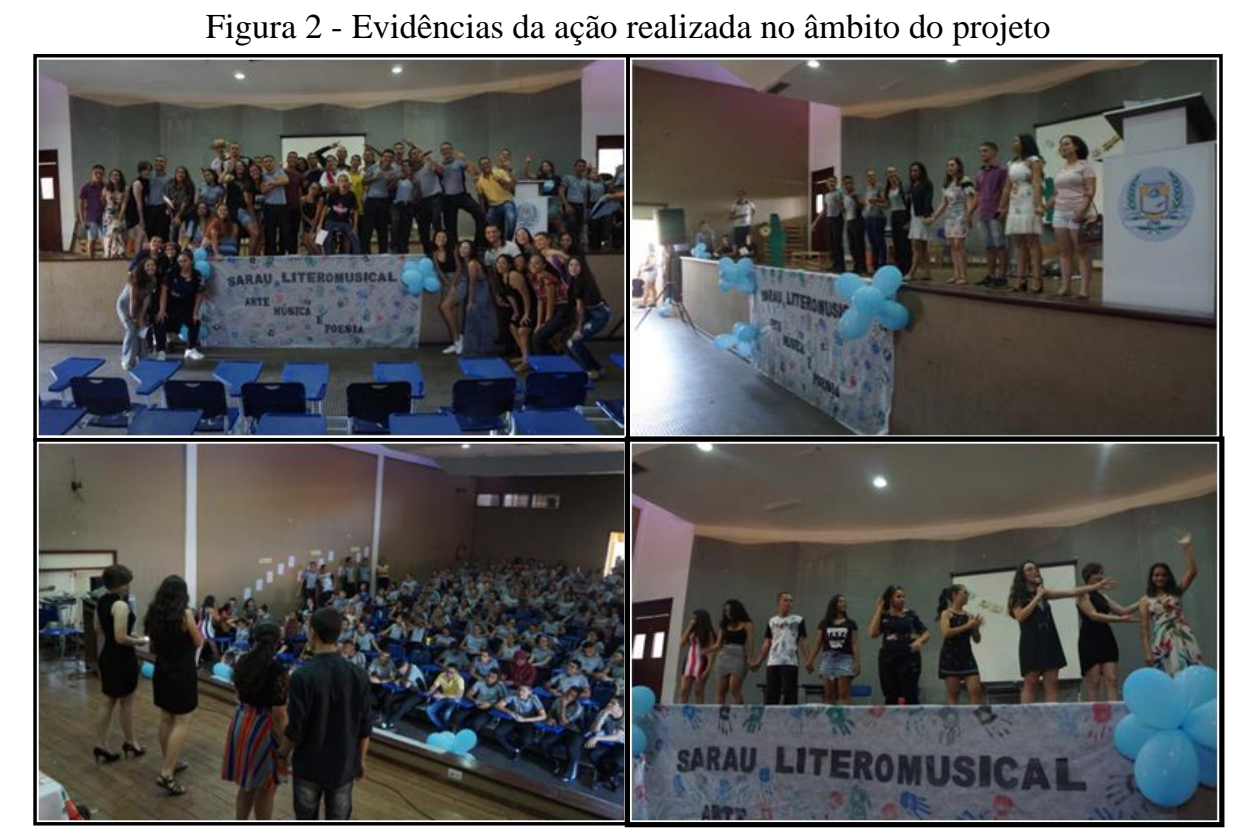

Fonte: ASCOM CPM, 2019.

Figura 3 - Evidências da ação realizada no âmbito do projeto

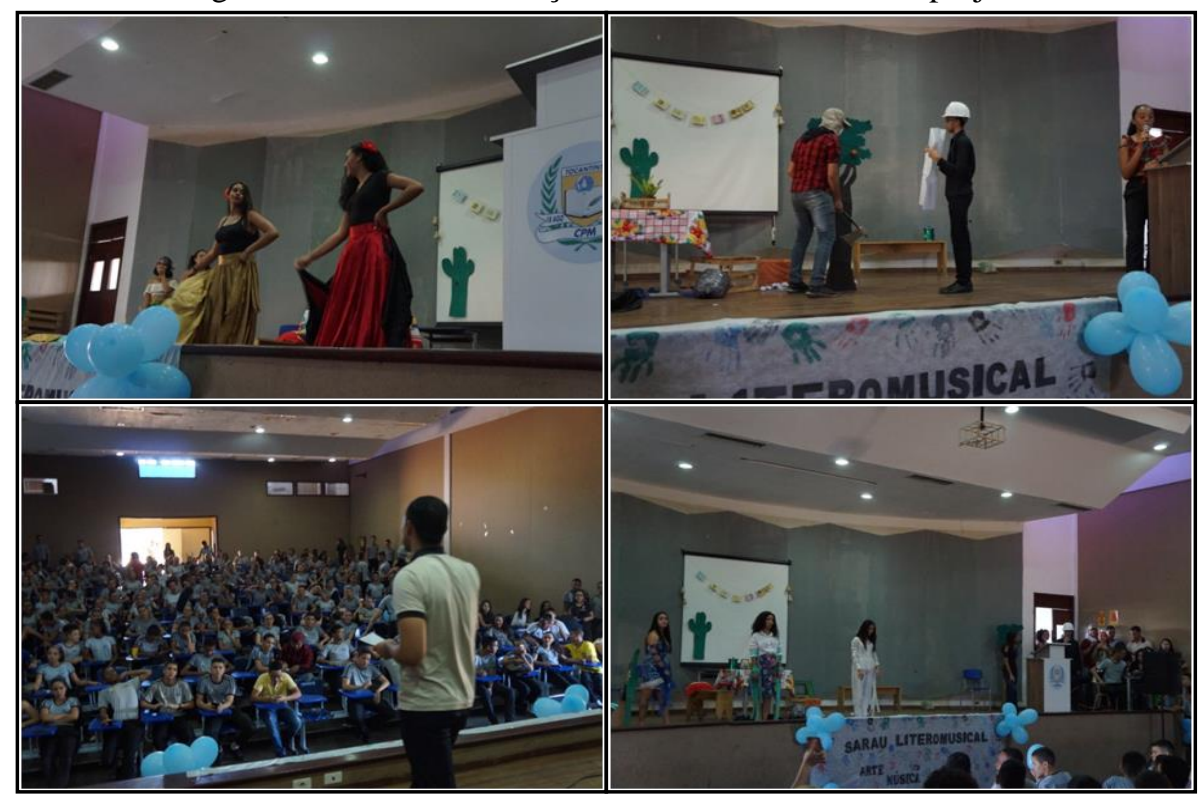

Fonte: ASCOM CPM, 2019.

É importante percebermos da valorização cultural local, da introdução de novas linguagens na sala de aula que não apenas a urbana de prestígio e escrita, da incorporação de novas tecnologias e de diferentes gêneros, não apenas aquelas indicadas pelas secretarias de educação, mas, sobretudo, aquelas que partem de uma necessidade ou realidade da comunidade/dos alunos (ROJO; MOURA, 2012, p.15). O aluno deve ser estimulado e sua curiosidade instigada à aula. É necessário dar sentido àquilo que estamos ensinando. É preciso, também, mudar o conteúdo programático das escolas para temas que de fato vão ser usados na vida: comunicação, finanças pessoais e a Constituição Federal, são alguns exemplos. A leitura 
e a escrita precisam fazer sentidos para a pessoa, caso contrário se tornará um mero fazer por fazer. Os objetivos dessas práticas sociais precisam ser socializados com quem irão construir o conhecimento para que o mesmo entenda e permita ser inserido em outras práticas sociais PCN (BRASIL, 1998, p. 41). Essa visão também é apontada pela Proposta Curricular do Ensino Médio - PCEM (TOCANTINS, 2009), pois percebe a leitura e a escrita como um processo que deve envolver o aluno em questões da realidade a partir de contextos socializados.

Posto isso, a prática docente deve ser realizada com base na promoção de saberes e o ensino deve ser mantido pelas relações estabelecidas entre professor e aluno com decisões partilhadas da escola para a capacidade reflexiva sobre aquilo que se quer alcançar. A Base Nacional Comum Curricular (BNCC) visa favorecer a fluência na compreensão da leitura, produção, criação, fruição e o "gradativo domínio de planejamento, revisão e produção, tendo em vista os contextos de circulação dos sujeitos na Educação Básica” (BRASIL, 2015, p. 33), perpassando a transposição didática que organizam os objetos de ensino da disciplina de Língua Portuguesa.

Com base nas acepções apresentadas, podemos inferir que os significados são construções sociais de leitura e escrita e a escola precisa incorporar isso em função da ciência discursiva. Nesse sentido, "o acesso à prática social da leitura deve dar ao aluno a possibilidade de recriar para si mesmo, criticamente, os significados que a escola enfatiza” (MOITA LOPES, 1994, p. 358), levando-o a construção da aprendizagem. O professor precisa despertar a necessidade de atualização da prática docente com base no reconhecimento do protagonismo das/dos estudantes, no estímulo às múltiplas práticas sociais comunicativas, na aplicação de situações comunicativas tangíveis e reais, nas experiências socioculturais ligadas ao momento histórico, ao espaço social e aos sujeitos envolvidos no processo participativo e construtivo do ensino e aprendizagem. Freire (1996) contempla essa discussão com a seguinte afirmação:

[...] ao estudo crítico corresponde um ensino igualmente crítico que demanda necessariamente uma forma crítica de compreender e de realizar a leitura da palavra e a leitura do mundo, leitura do contexto (FREIRE, 1996, p. 264).

Ressaltamos que a escola tem um papel político. Portanto, ao falar de aprendizagens, é necessário também apontar a escola como um sistema enunciativo de ações e ideias do sistema de ensino. É nela que o sujeito se torna questionador, inquieto e propositivo, e esse sujeito é habilitado a atuar em contextos diversos em que se mobilizem práticas de leitura e escrita. 


\section{CONSIDERAÇÕES FINAIS}

O Sarau é um projeto que acontecerá de forma contínua, no segundo semestre letivo envolvendo turmas da disciplina de Língua Portuguesa. É de inteira e livre participação dos alunos e equipe escolar no evento, cujo público-alvo sinta a arte presente na vida e reflita acerca das diferentes tramas apresentadas.

A continuidade da ação é necessária a fim de provocar sentimentos simbólicos que possam contribuir para a construção do imaginário social vinculado à linguagem artística. Diante do trabalho desenvolvido ao longo de dois meses em sala de aula com o gênero poema, ficou claro que os alunos realmente se envolveram com a proposta, pois a grande maioria deles liam os textos de forma atenciosa, procuravam entender a essência do que estava escrito, encontravam beleza e discutiam com os colegas, estabelecendo preferências por uma leitura e escrita mais elaborada. Observa-se que as atitudes dos alunos frente às atividades expostas depois de prontas, uma ao lado da outra, de autoria e em local visível, evidenciando a diversidade de tudo o que foi produzido, causou-lhes um estado de felicidade e orgulho pelo trabalho realizado e reconhecido também por outros colegas que elogiavam o produto final.

Pensar num trabalho que provoque o encontro entre a linguagem oral e a escrita é antes de tudo propiciar momentos em que o aluno se reconheça como alguém capaz, como sujeito do mundo, concreto, participativo e constituinte para a promoção de conhecimentos do meio em que está inserido. O aluno é, assim, entendido como um ser protagonista, uma vez que ele é considerado o número central do projeto. Essa postura é carregada de sentidos: autonomia, liberdade e utilidade. A visibilidade deste aluno ocorre uma vez que ele é inserido em práticas linguageiras e permite vivenciar essa prática, aprimorando e fundamentando suas ideias, sua voz, sua postura e sua construção coletiva, de modo que nesse espaço o aluno sinta-se motivado a estar em sala de aula e passa a ter posicionamentos críticos.

Assim, compete ao componente de Língua Portuguesa proporcionar aos estudantes experiências que contribuam para a ampliação das práticas de letramentos, de modo a possibilitar a participação significativa e crítica nas diferentes instâncias sociais, permeadas pela construção de saberes.

Com essa experiência, temos a percepção de que trabalhar com projetos estimulantes como o Sarau, que foca no aluno e concebe sua realidade como um fator de potencialidade a ser explorado é, entre outras coisas, atribuir oportunidades mais próximas da realidade do aluno, prevendo que ele se transforme a partir dessa realidade e inspire-se para uma mudança individual e coletiva significativa para o contexto em que vive. O que fica para todos é a 
percepção de que o professor não pode ficar amarrado ao programa e aos conteúdos, mas que perceba a real necessidade dos estudantes, de modo que sua prática seja direcionada para a formação de sujeitos críticos e autônomos, tornando o processo de ensino e aprendizagem para uma construção significativa.

\section{REFERÊNCIAS}

BAKHTIN, Mikhail. Estética da criação verbal. 4. ed. São Paulo: Martins Fontes, 2003.

BRASIL. MINISTÉRIO DA EDUCAÇÃO. Base Nacional Comum Curricular. Consulta Pública. Brasília, MEC/CONSED/UNDIME, 2015. Disponível em:

http://portal.mec.gov.br/seb/arquivos/pdf/portugues.pdf. Acesso em: 27 fev. 2020.

\section{BRASIL. MINISTÉRIO DA EDUCAÇÃO. Lei de Diretrizes e Bases da Educação}

Nacional. Lei $\mathrm{n}^{\circ}$ 9394, de 20 de dezembro de 1996. Estabelece as diretrizes e bases da educação nacional. Brasília, DF, 1996. Disponível em:

http://www.planalto.gov.br/ccivil_03/leis/L9394.htm Acesso em: 13 abr. 2020.

BRASIL. MINISTÉRIO DA EDUCAÇÃO. Parâmetros Curriculares Nacionais: terceiro e quarto ciclos do Ensino Fundamental: língua portuguesa. Secretaria de Educação Fundamental. Brasília: MEC/SEF, 1998. Disponível em: http://portal.mec.gov.br/seb/arquivos/pdf/introducao.pdf Acesso em: 27 fev. 2020.

CARVALHO, Alex Moreira. Aprendendo Metodologia Científica. São Paulo: Nome da Rosa, 2000.

CEREJA, William; VIANNA, Carolina Dias; DAMIEN, Christiane. Português contemporâneo: diálogo, reflexão e uso. 1. ed. São Paulo: Saraiva, 2016.

DESLANDES, Suely Ferreira. O projeto de pesquisa como exercício científico e artesanato intelectual. In: MINAYO, Maria Cecília de Souza; DESLANDES, Suely Ferreira. (Org.). Pesquisa Social: Teoria, método e criatividade. Rio de Janeiro: Vozes, 2009, p. 31-60.

FREIRE, Paulo. A importância do ato de ler: em três artigos que se completam. 41. ed. São Paulo: Cortez, 1992.

FREIRE, Paulo. Pedagogia da autonomia. Saberes necessários à prática educativa. São Paulo: Paz e Terra, 1996.

KLEIMAN, Ângela. O processo de aculturação pela escrita: ensino da forma ou aprendizagem da função. In: KLEIMAN, Angela; SIGNORINI, Inês. (Orgs.) O ensino e a formação do professor. Alfabetização de jovens e adultos. Porto Alegre: Artmed, 2000, p. $223-243$

LAJOLO, Marisa. Do mundo da leitura para a leitura do mundo. 6. ed. São Paulo: Ática, 2002.

MARCUSCHI, Luiz Antônio. Da fala para escrita: atividades de retextualização. 4 ed. São Paulo: Cortez, 2003. 
MOITA LOPES, Luís Paulo. Linguagem, interação e formação do professor. Brasília: Revista Brasileira de Estudos Pedagógicos, v. 75, n. 179, p. 301- 371, jan/jul. 1994. Disponível em: http://www.dominiopublico.gov.br/download/texto/me0000319.pdf Acessado em: 16 abr. 2020.

ROJO, Roxane; MOURA, Eduardo. Multiletramentos na escola. São Paulo: Parábola, 2012.

SERCUNDES, Maria Madalena Iwamoto. Ensinando a escrever. In: (Orgs.). GERALDI, João Wanderley; CITELLI, Beatriz. Aprender e ensinar com textos de alunos. v. 1. São Paulo: Cortez, 1997, p. 75-97.

SILVA, Eliseu Ferreira da; JESUS, Wellington Gomes de. Como e porque trabalhar com a poesia na sala de aula. Revista Graduando, v. 1, n 2, p. 21-34, 2011. Disponível em: http://www2.uefs.br/dla/graduando/n2/n2.21-34.pdf Acessado em: 28 jun. 2020.

TOCANTINS, SECRETARIA DE EDUCAÇÃO. Referencial Curricular do Estado do Tocantins: Ensino Fundamental - Língua Portuguesa. Tocantins, 2009. Disponível em: https://seduc.to.gov.br/publicacoes/publicacoes/documento-curricular-do-tocantins--educacao-infantil-e-ensino-fundamental/ Acesso em: 12 abr. 2020.

ZANINI, Marilurdes. Uma visão panorâmica da teoria e da prática do ensino de língua materna. Acta Scientiarum. Human and Social Sciences, v. 21, p.79-88, 1999. Disponível em: http://periodicos.uem.br/ojs/index.php/ActaSciHumanSocSci/article/view/4189 Acessado em: 12 abr. 2020.

Recebido em: 28 de julho de 2020.

Aprovado em: 18 de novembro de 2020. 